\title{
An automatic classification and robust segmentation procedure of spatial objects
}

\section{Fabio Crosilla • Domenico Visintini • Francesco Sepic}

\section{Erratum to: Stat. Meth. \& Appl. DOI 10.1007/s10260-006-0033-5}

On page 332 there is a mistake in the formula in the middle of the page. The wrong version is:

$$
F=\left\langle x_{u}, x_{v}\right\rangle=1+\left(\frac{\partial z}{\partial E_{i}}\right)\left(\frac{\partial z}{\partial N_{i}}\right)
$$

The correct version is:

$$
F=\left\langle x_{u}, x_{v}\right\rangle=\left(\frac{\partial z}{\partial E_{i}}\right)\left(\frac{\partial z}{\partial N_{i}}\right)
$$

The online version of the original article can be found at http://dx.doi.org/10.1007/s10260-006-0033-5.

F. Crosilla $(\varangle) \cdot$ D. Visintini · F. Sepic Department of Georesources and Territory, University of Udine,

via Cotonificio, 114 I-33100 Udine, Italy e-mail: fabio.crosilla@uniud.it 